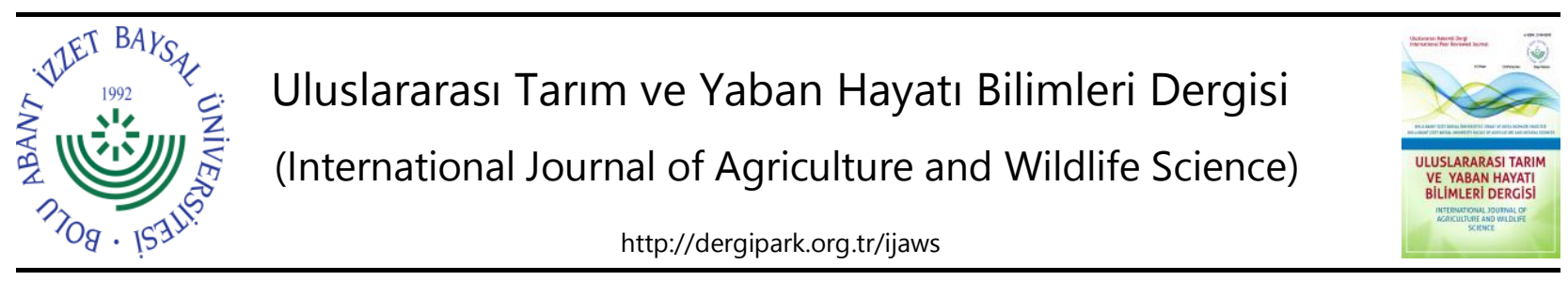

Araştırma Makalesi

\title{
Ekolojik Köprülerin Potansiyel Yer Seçimleri: İzmir-Çeşme Otoyolu Örneği ${ }^{* \star}$
}

\author{
Ali Uğur Özcan \\ Çankırı Karatekin Üniversitesi, Orman Fakültesi, Peyzaj Mimarlığı Bölümü, Çankırı \\ Geliş tarihi (Received): 28.12.2020 \\ Kabul tarihi (Accepted): 02.03.2021
}

\begin{abstract}
Anahtar kelimeler:
Habitat uygunluğu,

Özet. Ulaşım ağları peyzajları bölerek biyoçeşitlilik üzerinde birçok olumsuz etkiye yol açmaktadır. bağlantı, yaban hayatı, ekolojik köprü

Ekolojik köprüler parçalanmış peyzajların birleştirilerek yaban hayvanların güvenli geçişine imkan tanımaktadır. Ekolojik köprülerin yer seçiminde yaban hayatı araç kazalarından vericilerle hayvanların izlenmesine kadar birçok yöntem kullanılmaktadır. Fakat bu yöntemler hem maliyetli hem de uzun zaman alabilmektedir. Bunun sebepten dolayı ekolojik geçitlerin potansiyel yerlerinin belirlenmesinde CBS tabanlı modellerden faydalanılmaktadır. Bu çalışma için örnek alan olarak seçilen İzmir-Çeşme Otoyolu'nda CBS/Habitat Uygunluk/Bağlantı modeli kullanılarak ekolojik köprüler için potansiyel yer tespitleri yapılmıştır. Hedef tür olarak yaban domuz Sus Scrofa seçilmiştir. Peyzaj koridorlarının ve bağlantı düğümlerinin konumsal haritaları en az maliyetli yöntem ile belirlenmiştir. Çekirdek alan üzerindeki bağlantılar dentrik ağ bağlantısı oluşturmuştur. Bağlantı düğümlerine göre otoyolun yaklaşık olarak \%8'inin potansiyel ekolojik köprü için en uygun yer olduğu tespit edilmiştir. Ekolojik köprüler için tahsis edilen kısıtlı bütçe ve yüksek maliyetler yüzünden en uygun yerin seçilmesi

*Sorumlu yazar auozcan@karatekin.edu.tr gerekmektedir. Bağlantı modelleri ekolojik köprü yer seçiminde birçok konumsal verinin kullanılabilmesi, geliştirilebilmesi, kısa sürede sonuç vermesi ve potansiyel alanların tespit edilmesi gibi birçok avantaj sağlayabilecektir.
\end{abstract}

\section{Potential Location Selection of Ecological Bridges: İzmir-Çeşme Highway}

\begin{tabular}{|c|c|}
\hline Keywords: & Abstract. Transport networks divide landscapes, causing many negative impacts on biodiversity. \\
\hline $\begin{array}{l}\text { Habitat suitability, } \\
\text { connectivity, } \quad \text { wildlife, } \\
\text { ecological bridge }\end{array}$ & $\begin{array}{l}\text { Ecological bridges allow safe passage of wildlife by connecting fragmented landscapes. In the spatial } \\
\text { selection of ecological bridges, many methods are used, from wildlife vehicle collision to tracking } \\
\text { animals with collar. However, these methods are both costly and time consuming. For this reason, } \\
\text { GIS-based models are used in determining the potential locations of ecological passages.. Potential } \\
\text { spatial locations were mapped for ecological bridges by using the GIS/Habitat Suitability/Connectivity } \\
\text { model on the İmir-Çeşme Highway, which was selected as a case area for this study. Wild boar Sus } \\
\text { Scrofa was selected as the target species. Spatial maps of landscape corridors and connection nodes } \\
\text { were determined with the at least cost method. The corridors between the core areas have formed a } \\
\text { dentric network connection. According to the connection nodes, it has been determined that } \\
\text { approximately } 8 \% \text { of the highway is the most suitable location for potential ecological bridges. Due to } \\
\text { the limited budgets and high costs required for the construction of ecological bridges, the most } \\
\text { suitable location should be selected. In ecological bridge location selection, connection models can } \\
\text { provide many advantages such as the ability to use and develop many different spatial data, to } \\
\text { extrapolate in a short time and to identify potential areas. }\end{array}$ \\
\hline
\end{tabular}




\section{GíRiş}

Ulaşım sistemleri, dünya çapında her noktaya ulaşabilen bir ağ oluşturmakta ve yaban hayatı üzerinde birçok olumsuz etkiye yol açmaktadır (van der Ree ve ark., 2015). Yollar, araç çarpışmaları (Özcan ve Özkazanç, 2020), habitat parçalanmaları ve kayıpları ve bağlantı ve bariyer etkileri (Laurance ve ark., 2009; Forman, 2012) veya bireysel davranışsal değişiklikler gibi olaylar ile yaban hayatı popülasyonları üzerinde önemli etkilere sahiptir. Bununla birlikte, yolların yaban hayatına olan ekolojik etkileri yolun kendisinden daha fazla bir alanda meydana gelmektedir (McRae ve ark., 2012). Yol etkisi bölgesi, önemli ekolojik etkilerin tespit edilebildiği yolun kenarına olan mesafedir (Forman ve Alexander, 1998). Bu yüzden bazı hayvanlar yolu bariyer olarak kabul eder ve geçme teşebbüsünde bulunmaz. Eigenbrod ve ark. (2009), amfibilerin tür zenginliği ve nispi bolluğu üzerindeki yol etki bölgesinin yedi türden dördü için yol kenarından 250 - $1000 \mathrm{~m}$ aralıkta güçlü olumsuz etkileri olduğunu tespit etmiştir. Yine, orman ve mera kuş türlerinin bolluğunun, çeşitliliğinin ve üreme faaliyetlerinin yollardan 300-1000 m mesafede önemli ölçüde azaldığı görülmektedir (Helldin ve Seiler, 2003). Bunun yanında bazı otçullar için yolların meydana getirdiği açıklıklar veya bazı leşçiler için karayollarındaki leşler yollara çekiciliği arttırabilmektedir (Whittington-Jones ve ark., 2011). Bu da daha fazla araç kazalarına yol açabilmektedir.

Yolların parçaladığı habitatlar arasında bağlantının kurulması veya yaban hayatı-araç çarpışmalarından kaynaklanan hayvan ölümlerinin azaltılması için alt geçitler, üst geçitler ve çitler gibi birçok önlem kullanılabilmektedir (Downs ve Horner, 2012). Bu önlemler 150 metre genişliğinde bir üst geçit olabileceği gibi yeniden tasarlanmış bir menfez de olabilmektedir. Uyarı işaretleri, hayvan bulma sistemleri, tel çitler yaban hayvanların daha güvenli geçmesini sağlayabilmektedir (Huijser ve ark., 2007). Ama üst veya alt geçitler tel çitlerle birlikte doğrudan habitatları birleştirdiği ve trafik kazaları için güvenli olduğundan tercih edilen çözümlerden en önemlisidir (Dodd ve ark., 2007).

Ekolojik geçitlerin etkinliği tamamen doğru yere yerleştirilmesi ile orantılıdır (Glista ve ark., 2009). Ancak, bu yapılara tahsis edilen kısıtı bütçe ve yüksek maliyetler bu geçişlerin sayısını sınırlamaktadır. Bu nedenle, bu yapıların konumunun, geçidin olumsuz etkileri azaltmadaki etkinlikleri ile optimize edilmesi çok önemlidir (Bastille-Rousseau ve ark., 2018). Doğru seçilmemiş alanlar tam olarak potansiyel faydaları sağlamayacaktır çünkü yaban hayvanları yapıları kullanmayacaktır (Ruediger, 2001). Bağlantıları sağlayan ekolojik koridorların veya geçitlerin nereye konumlandıılacağı genel olarak yaban hayatı araç çarpışmalarının mekânsal dağılımı ile ilişkilendirilmektedir (Clevenger ve Huijser, 2011). Yaban hayvanlarına takılan GPS izleme sistemleri (Horne ve ark., 2007; Bastille-Rousseau ve ark., 2018) veya yollar boyunca yapılan araştırmaların izlenmesinden elde edilen veriler de kullanabilmektedir (Scheick ve Jones, 1999). Yine de bu çalışmaların doğru sonuç vermesi için yıllar gerekmektedir. Özcan (2018) Çankııı-Kıııkkale karayolunda yaban hayatı araç çarpışmalarının konumsal olarak her yıl değiştiğini belirlemiştir. Tüm yollarda bu verileri elde etmek için oldukça uzun zaman, ekonomi ve teknik elemana intiyaç duyulabilmektedir. Bu nedenle, parçalı peyzajlarda habitat bağlantısını maksimum düzeyde artıran yapılar için en uygun yerleri seçebilen mekansal karar modellerine ihtiyaç vardır (Downs ve Horner, 2012). Coğrafi Bilgi Sistemleri (CBS) ile habitat bağlantılarının modellenmesi, yaban hayatı geçiş yapılarının potansiyel konumlarının belirlenmesinde son yıllarda sıkça kullanılan bir yöntemdir (Wierzchowski ve ark., 2019; Panagoda ve Weerasinghe, 2019). Özcan ve Erzin (2020) İç Anadolu için kalıntı ormanlar arasındaki ekolojik bağlantıları ve karayollarını kestiği alanlar için potansiyel ekolojik geçit konumlarını belirlemiştir.

Bu çalışmada Türkiye'de yapılması düşünülen yaban hayatı geçişlerinin habitat uygunluk/bağlantı modelleri ve CBS kullanılarak konumsal olarak potansiyel alanlarının belirlenmesi için uygulanabilir bir rehber oluşturulması amaçlamıştır. Ekolojik köprünün gerekliliğinden ziyade yer seçimi üzerine odaklanılmıştır. Bu amaç için üzerinde bir geçit yapılan ve daha başka geçitlerinde yapılmasının düşünüldüğü İzmir-Çeşme Otoyolu örnek alan olarak seçilmiştir.

\section{MATERYAL VE METOT}

\section{Çalışma Alanı}

Çalışma alanı olarak Türkiye'nin en batı ucunda yer alan Çeşme-Urla Yarımadası ve yarımadayı iki bölüme ayıran İzmir-Çeşme Otoyolu seçilmiştir (Şekil 1). Çalışma alanı Çeşme, Urla ve Karaburun ilçelerinden oluşmaktadır. Bu üç ilçenin alanı yaklaşık olarak $1379 \mathrm{~km}^{2 \prime}$ dir. Yarımadanın büyük bir kısmı ormanlardan oluşmaktadır. Köppen iklim sınıflamasına göre "Kışı ılık, yazı çok sıcak ve kurak iklim"in (Akdeniz iklimi Csa) (Yılmaz ve Çiçek, 2019) hâkimiyetinde yer alan yarımadada orman, maki ve frigana olmak üzere üç farklı vejetasyon formasyonu dağılış göstermektedir (Soykan ve ark., 1993). Yarımadadaki ormanların baskın ağacı kızılçam (Pinus brutia Ten.)'dır. Maki toplulukları doğal olarak kızılçam (Pinus brutia Ten.) ormanlarının ağaçcık katını oluşturmaktadır. Bölgede kızılçam ormanlarının çeşitli yollardan ortamdan kaldıııldığı yerlerde ortam bu 
ağaçcıklar tarafından kaplanarak kapalılık oluşturmuştur. Bu türlerden en önemlisi kermes meşesidir (Quercus coccifera). Yayılış alanı kızılçam ile uyumludur. Ayrıca maki elemanlarından özellikle ışığı seven adaçayı yapraklı laden (Cistus salviifolius), keçiboğan (Calycotome villosa), katran ardıcı (Juniperus oxycedrus) gibi türler ile gölgeye dayanaklı sandal ağacı (Arbutus andrachne L.), ağaç fundası (Erica arborea), sakız ağacı (Pisticia lentiscus), akçakesme (Phillyrea latifolia) ve tesbih (Styrax officinalis) türleri ağılıklı olarak bulunmaktadır. Çeşme-Karaburun yarımadaları, orman tahribine en fazla uğrayan alanların başında gelmektedir. Bekat (1980), Günal (1986) ve Sezer (1993)'in Karaburun'da yapmış olduğu çalışmalarda orman tahribi sonucu makilerin, onun da tahrip edilmesi sonucu garig vejetasyonun yaygınlaştığını belirlemiştir. Yarımadada orman dışında mevcut alan kullanım faaliyeti tarımdır. Tahıl ürünleri, narenciye, zeytin ve bağcılık yaygındır. Yarımadada yer alan üç ilçenin nüfusları toplamı 2019 yılında 122461 kişidir (TÜiK, 2020). Fakat bu nüfus yaz aylarında yaklaşık olarak dört katına kadar çıkmaktadır. Örneğin Çeşme ilçesindeki konut sayısı 55733 adet olup bunun \%70'i 3-4 aylık kullanımlardır (Çeşme Kaymakamlığı, 2020)

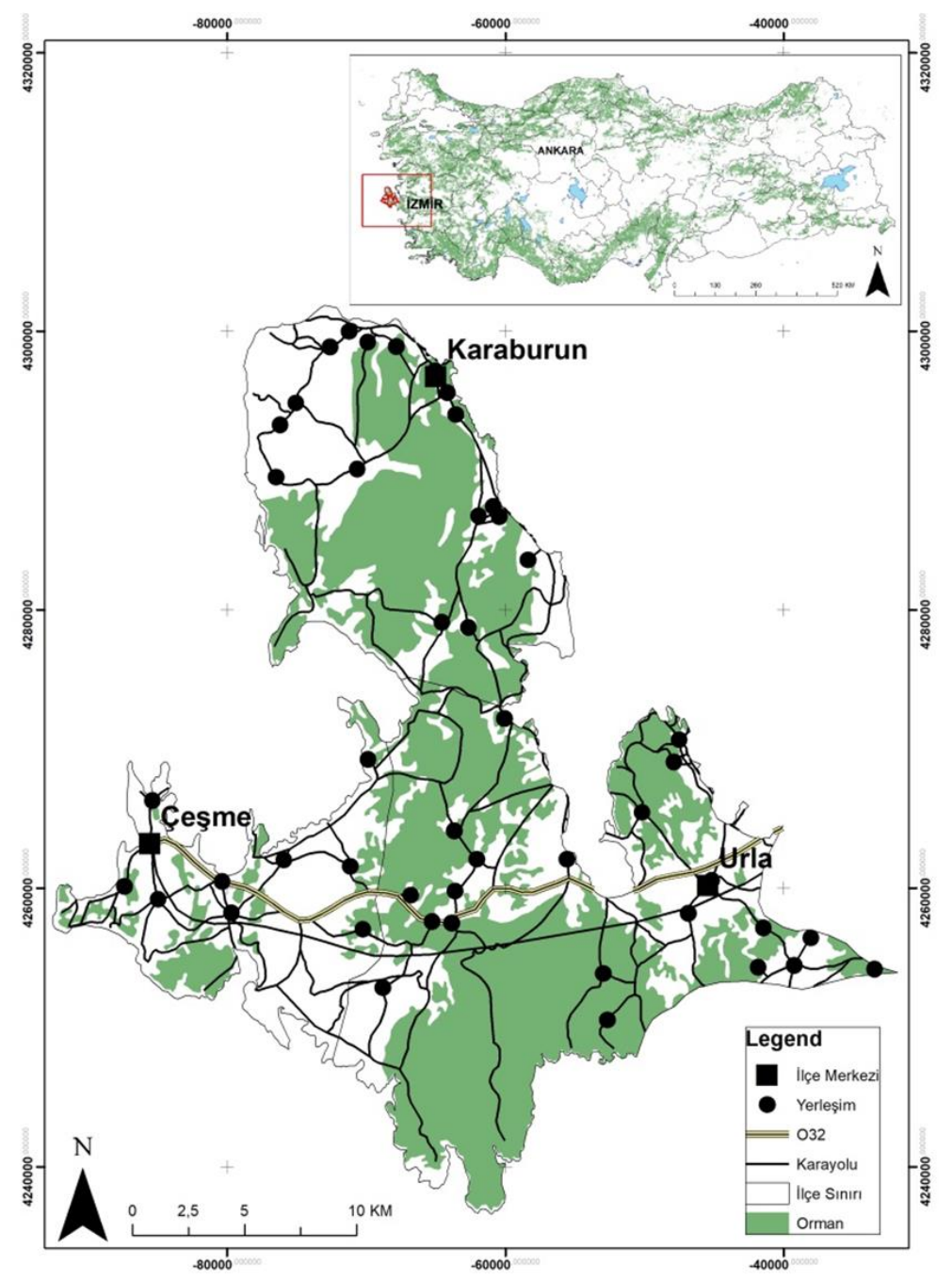

Şekil 1. Çalışma alanı.

Figure 1. Study area.

\section{Metot}

Ekolojik bağlantıların belirlenmesi ve potansiyel ekolojik köprü yer seçiminde grafik teori yaklaşımına göre devre modeli kullanılmıştır. Grafik teori yaklaşımına göre devre modelinin oluşturulması öncelikli olarak hedef tür/türler seçimi, çekirdek alanların belirlenmesi, habitat uygunluk haritaları veya peyzaj direnç haritaları ve least-cost gibi araçlar ile ekolojik bağlantıların oluşturulması olarak dört aşamadan meydana gelmektedir.

Korunan alanlar arasındaki ekolojik koridorların belirlenmesi için temel başlangıç hedef türlerin seçilmesidir (Gurrutxaga ve ark., 2010). Bir hedef tür, büyük olasılıkla diğer türlerin çoğuna yarar sağlayacağı bir "şemsiye türü" olabilmektedir. Klasik biçimde ve yerel ölçekte şemsiye türü kavramı, geniş kapsamlı bir türün popülasyonunun minimum alan gereksinimlerini ifade eder (Wilcox, 1984). Bu kavram, geniş alan gereksinimleri olan türler için yeterli alan sağlamanın aynı zamanda daha sınırlı mekânsal ihtiyaçlara sahip bir tür kümesini de barındıracağı sonucunu veren bir varsayıma dayanmaktadır. İri vücut büyüklüğüne sahip organizmalar, geniş 
alan kullanımına (home range) sahip olma eğiliminde oldukları için (McNab, 1963), bu türlerin yaşayabilir popülasyonlarını muhafaza etmek, büyük yaşam alanlarının korunmasını gerektirir. Bu nedenle, iri vücut büyüklüğüne sahip organizmalar, muhtemel şemsiye türler olarak tercih edilmektedir. Çalışma alanında yaban domuzu (Sus scrofa), çakal (Canis aureus), tilki (Vulpes vulpes) ve porsuk (Meles meles) gibi orta ve büyük memeli türleri bulunmaktadır. Hepcan ve ark. (2009 ve 2013) İzmir için hazırladıkları ekolojik ağ çalışmasında hedef tür olarak belirledikleri karakulak (Caracal caracal) için son 10 yıldır ve çizgili sırtlan (Hyena hyena) için 40 yıldır çalışma alanında olduğuna dair bir kanıt bulunmamaktadır. Bu yüzden çalışma alanının en büyük memelisi yaban domuzudur. Yaban domuzunun hedef tür olmasının önemli bir diğer sebebi de otoyolda ölümlü, yaralamalı ve maddi hasarlı birçok kazaya sebebiyet vermesidir. Dünya'da yaban domuzu araç çarpışmaları sonucunda ciddi sorunlar oluşmaktadır. Örneğin İspanya'da 2006-2012 yılları arasında meydana gelen yıllık ortalama 10657 (min 7948- maks. 14390) yaban hayatı araç çarpışmasının 5005 (min: 3626- maks: 6827) adeti yaban domuzudur (Sáenz-de-Santa-María ve Tellería, 2015). Yaban domuzları ağırlıklı olarak otobur bir hayvandır. Her türlü habitata uyum sağlamış olup besinlerinin büyük bir kısmını tarımsal alanlardan sağlayabilmektedir. Yaban domuzlarının yetişkin erkekleri tek gezerken dişiler, yavrular ve yetişkin olmayan erkekler sürüler oluşturabilmektedir. Güçlü uyum yeteneği ve üreme hızı, sürü halinde hareket etmesi ve ağırlıklarının fazla olmasından dolayı kazaların yoğunluğunun şiddetinin artmasına yol açabilmektedir.

Ovaskainen (2013), teorik gerekçeye dayanarak, eko kanalların (veya yaban hayatı geçiş köprülerinin) inşasının, yalnızca ekoduct 500-5000 hektardan daha büyük koruma alanlarını birbirine bağlaması durumunda mevcut korunan alanların boyutunu artırmaktan daha uygun maliyetli olduğunu varsaymıştır. Çalışma alanındaki çekirdek alanlar belirlenirken hedef türün ekolojik istekleri göz önünde bulundurulmuştur. Bunun için orman meşcere haritaları kullanılarak alanı öncelikli olarak 2500 hektarın üzerindeki bütün orman yamaları çıkarılmış ve sıralanmıştır. Karayolunun ve yerleşimin parçaladığı en büyük dört alan çekirdek alan olarak belirlemiştir.

Devre teorisinden bağlantı modelleri grafiklere uygulanmaktadır (Frank, 1969). Grafikler, kenarlarla birbirine bağlanmış düğüm kümelerinden (Bir raster peyzajındaki habitat yamalarını, popülasyonları veya hücreleri temsil eden bağlantı noktaları) oluşan ağlardır. Devre teorisinden elde edilen en basit bağlanabilirlik ölçüsü direnç mesafesidir (Klein ve Randic, 1993), tüm grafik kenarları analog dirençlerle değiştirildiğinde bir çift düğüm arasındaki etkili direnç olarak tanımlanan bir mesafe ölçüsüdür. Direnç mesafesinin uygun bir özelliği, düğüm çiftleri arasında ölçülen direnç mesafelerinin, daha fazla bağlantı eklendikçe azalmasıyla, düğümleri birbirine bağlayan birden çok yolu içermesidir. Yani, hem minimum hareket mesafesini/maliyetini hem de alternatif yolların mevcudiyetini içermektedir (McRae ve ark., 2008). Grafik yöntemi ile ekolojik bağlantıların tahmin edilmesi için CBS tabanlı Circuitshape aracı (Shae ve McRae, 2008) kullanılmıştır. Araçta çekirdek alanların konumsal tabakası (KPA Key protection area) ve hedef türün hareketine peyzaj içerisindeki direncinin tabakası (Habitat uygunluk haritası) olmak üzere iki farklı katman kullanılmaktadır. En düşük maliyetli koridorlar, yama çiftleri arasında tek bir yol yerine en düşük maliyetli bir yüzey üretilmiştir (McRae ve Kavanagh, 2011).

Çizelge 1. Yaban domuzu için uygunluk değerleri (Bosch ve ark., 2014; Rho, 2015; Rutten ve ark., 2019 'den uyarlanmıştır). Table 1. Suitability values for wild boar (adapted from Bosch et al., 2014; Rho, 2015; Rutten et al., 2019).

\begin{tabular}{lll}
\hline Faktör & Alt faktör & Uygunluk değerleri \\
\hline & Kentsel alanlar & 1 \\
& Maden alanı & 1 \\
& İnşaat alanı & 1 \\
& Kentsel yeşil alanlar & 5 \\
& Barajlar & 5 \\
Arazi Kullanımı & Sulu tarım & 40 \\
& Kuru tarım & 50 \\
& Meyvelik & 50 \\
& Mera & 70 \\
& Çayırlık & 70 \\
& Orman & 95 \\
\hline \multirow{4}{*}{ Yollar } & $<1000$ taşıt/gün & 20 \\
& $1000-5000$ taşıt/gün & 10 \\
& $5000-10000$ taşıt/gün & 7 \\
Akarsular & $10000-20000$ taşıt/gün & 3 \\
\hline
\end{tabular}


Ekolojik bağlantıların tasarımında önerilen peyzaj bağlantı modelinin kullanımı yoluyla peyzaj matrisinin hedef türün hareketliliğini hangi derecede etkilediği veya sınırlandırdığı varsayımına dayanan direnç haritaları hazırlanmıştır. Grafik yöntemini kullanan CBS araçlarında hem uygunluk (Circuitshape) hem de direnç (least cost) kullanılabilmektedir (Urban ve ark., 2009). Peyzaj direnç değerleri ile habitat uygunluk değerleri birbirini bire (\%100) tamamlamaktadır. Yani birbirlerinin ters değerleridir. Kullanılan direnç modellerinde direnç değişkenlerinin seçimi ve derecelendirilmesi oldukça önem arz etmektedir. Direnç/uygunluk yüzeylerinin belirlenmesinde birçok değişken göz önüne alınmaktadır (Zeller ve ark., 2012). Bu çalışma için değişken olarak, Zeller ve ark. (2012)'e göre direnç yüzeyleri/uygunluk değerleri oluşturmada en sık kullanılan değişkenler olan arazi kullanımı, ulaşım hattı ve hidrolojik yapı seçilmiştir (Çizelge 1). Yaban domuzuna ait habitat uygunluk değerleri Bosch ve ark. (2014), Rho (2015) ve Rutten ve ark. (2019) çalışmalarından uyarlanmıştır. Peyzaj direnç/uygunluk yüzeylerinin oluşturulmasında değerler ile birlikte asıl önemli olan kullanımların hiyerarşik sıralamasının doğru olmasıdır.

Arazi kullanımlarının sınıflandırılmasında, Orman haritaları ve 2018 haritaları (COPERNICUS, 2020) kullanılmıştır. Ulaşım ağı için ortalama günlük trafik yoğunluğu ile ilgili olarak karayolu hattı veri setleri kullanılmıştır (KGM, 2020). Çalışma ölçeği 1:25.000 ve raster (hücre) çözünürlüğü 10 metredir.

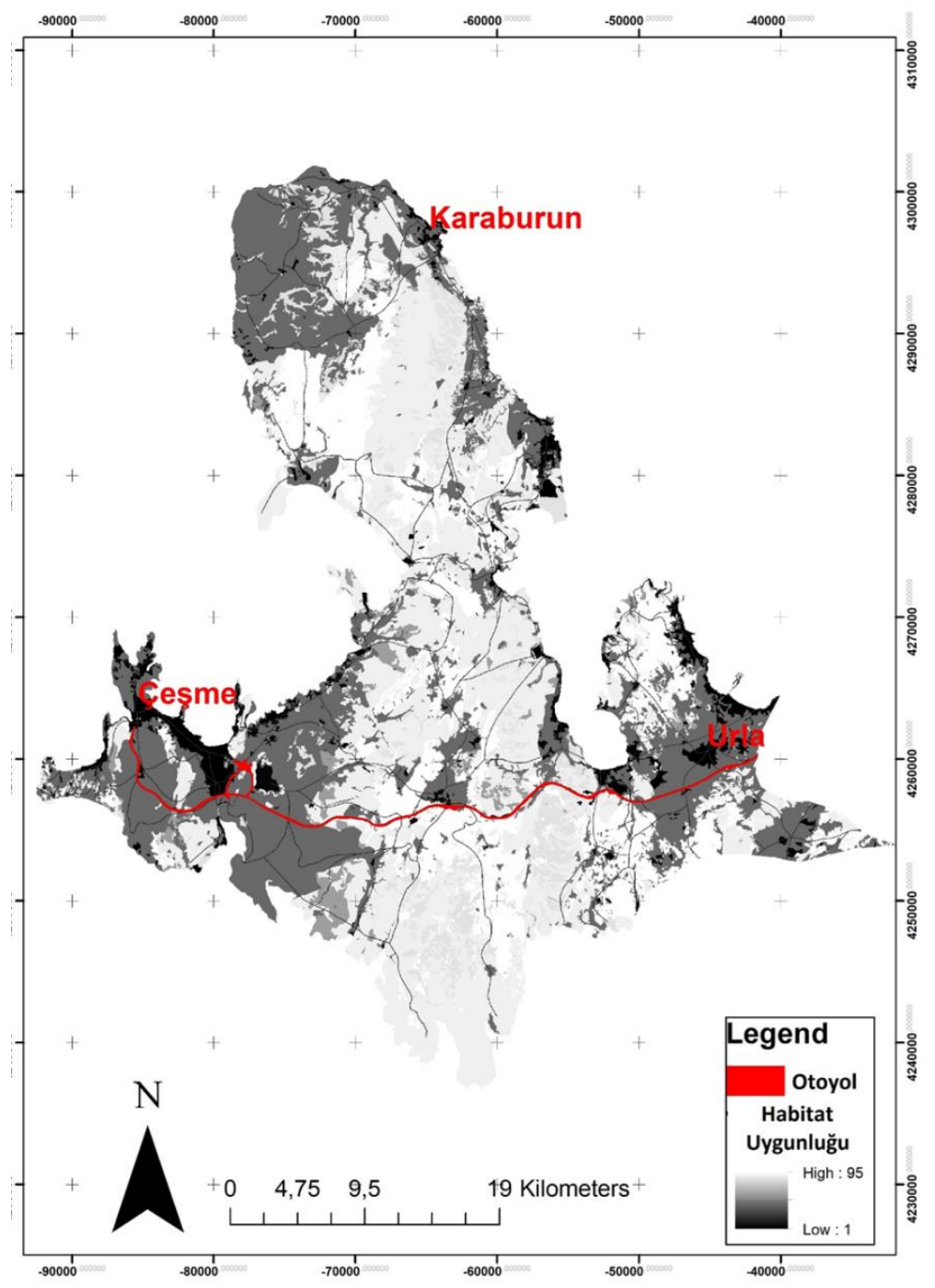

Şekil 2. Yaban domuzu için habitat uygunluk haritası.

Figure 2. Habitat suitability map for wild boar.

\section{BULGULAR}

İzmir Çeşme Otoyolu üzerinde CBS destekli habitat uygunluk/bağlantı modelleri ile yaban hayatı geçişlerini sağlayan ekolojik köprülerin yer seçimi için potansiyel mekânsal dağılımları elde edilmiştir. Şekil 3'de bağlantılarda sıcak renkler (kırmızı-0.1 ve sarı-1) daha yüksek koridor kalitesini ve soğuk renkler (turuncu) daha düşük kaliteli koridorları göstermektedir. Koridorlar, maliyet ağırlıklı 10 kilometrelik direnç maliyetiyle 
kesilmektedir. Koridorlar arasında görülen boşluklar, yüksek peyzaj direncine veya düşük habitat uygunluğuna işaret eder ve bu alanlarda akımın tamamen kesildiğinin önemli bir göstergesidir. Bağlantı düğümlerine göre otoyolun yaklaşık olarak \%8'i potansiyel ekolojik köprü için uygundur.

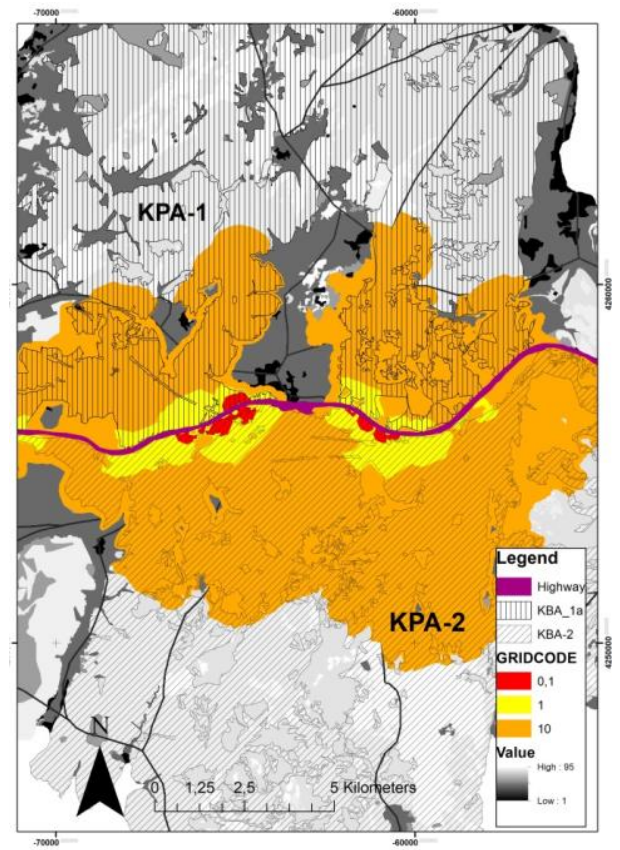

a

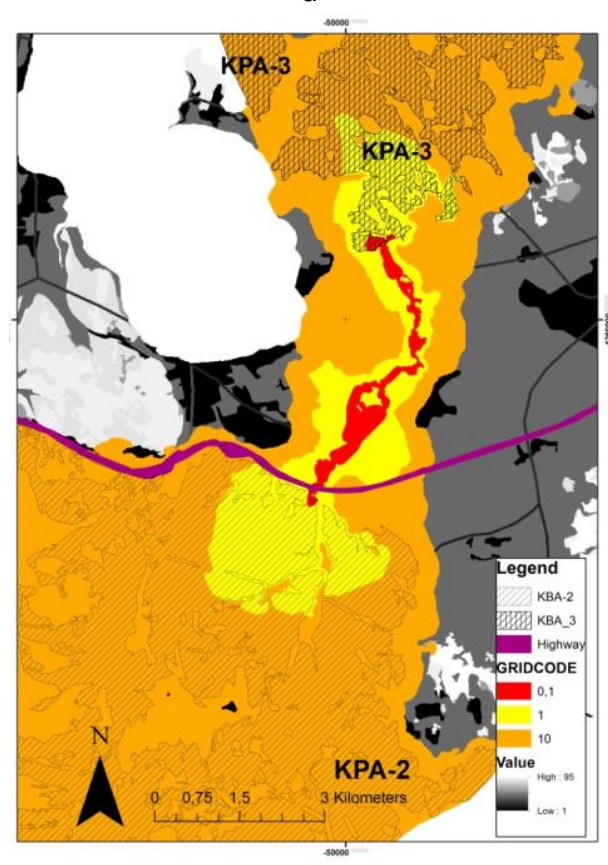

C

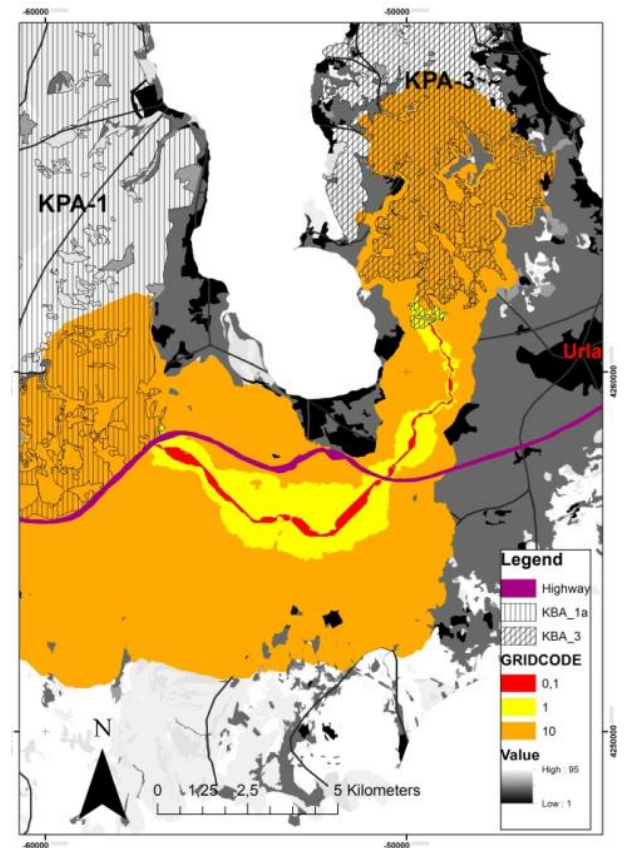

b

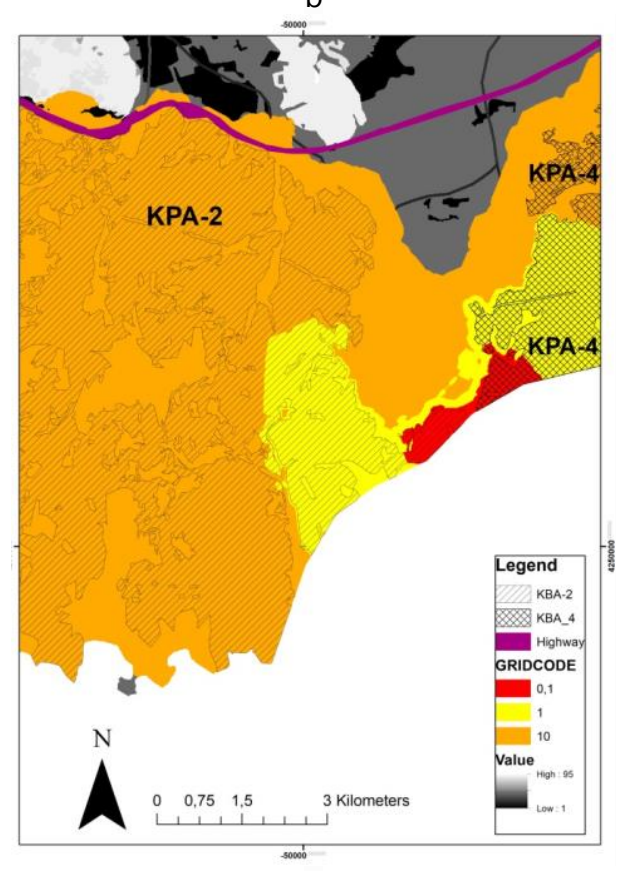

d

Şekil 3. İzmir Çeşme Otoyolu üzerinde ekolojik köprülerin yerleştirilebileceği potansiyel alanlar a) KPA1 ile KPA2 arasında b)KPA1 ile KPA3 arasında c)KPA2 ile KPA3 arasında d) KPA3 ile KPA4 arasında.

Figure 3. Landscape resistance values maps for variables a) Resistance map for 2000 land uses, b) Resistance map for 2018 land uses, c) Stream resistance map d) 2000 road resistance map, e) 2018 road resistance map.

İzmir Çeşme otoyolu ile bölünen 4 büyük çekirdek alan arasındaki en az maliyet yollarının geçtiği bağlantı düğümlerini veya potansiyel koridorları belirlenmiştir (Şekil 3). KPA1 (Karaburun Yarımadası) ile KPA2 arasındaki potansiyel koridorlar en güçlü bağlantı düğümlerine sahiptir. Aynı zamanda bu bölgedeki bağlantılar dentrik ağ bağlantısı oluşturmaktadır. Bunun en büyük sebebi orman özelliğine sahip iki çekirdek alanı İzmir Çeşme Karayolunun ve İzmir Çeşme otoyolun bölmesidir. Aynı zamanda KPA1 çekirdek alanını güneyden kuzeye doğru kama biçimiyle ikiye bölen tarım ve yerleşim alanlarının bulunmasıdır. Peyzajın oldukça geçirgen olduğu ve en uygun maliyetli yolun alternatif yollardan sadece çok az optimal olduğu alanlar, daha az koridor yoğunluğunun geniş alanları ile belirtilmektedir. Tersine, tahmin edilen koridor yollarının dar olduğu alanlar, analiz alanında, 
optimum koridor yolunu çevreleyen yerel peyzaj direncinin yüksek olduğu yerleri gösterir ve mevcut hareket yolu seçeneklerini sınırlamaktadır (Cushman ve ark., 2013). KPA1 ile KPA3 arasındaki bağlantı iki çekirdek alan arasında yerleşim, tarım alanları ve otoyol yüzünden tamamen kesilmiş ve KPA2 çekirdek alan üzerinden bağlantılar oluşturulabilmiştir. Urla ilçe merkezinin kuzeyinde kalan ve yarımada olan KPA3 çekirdek alanının diğer çekirdek alanlar ile bağlantısı çok zayıflamıştır. Zaten bağlantının daralması o bölgedeki yerleşim ve tarım alanlarının arttığının önemli bir göstergesidir. KPA2 ile KPA4 çekirdek alanlarının ikisi de otoyolun güneyinde kalmaktadır. Özellikle yerleşim ve tarım alanlarının yoğunluğu nedeniyle en güneyde bağlantı oluşturulabilmiştir. Ama iki çekirdek alan arasındaki bağlantının devam ettiği ortadadır. KPA3 ile KPA4 çekirdek alanlarının arasındaki bağlantı da yine Urla ilçesinin şehir merkezi ve köylerinin genişlemesi ve de tarım alanları yüzünden azalmıştır. KPA3 ile KPA4 arasındaki bağlantı KPA1 çekirdek alanında olduğu gibi KPA2 çekirdek alanı kullanılarak oluşturulmuştur.

\section{TARTIŞMA VE SONUÇ}

Ulaşım ağları büyümeye devam ettikçe, yaban hayatı üzerindeki olumsuz ekolojik etkilerin de artarak katlanacağı aşikardır. Olumsuz etkilerin azaltması için daha etkili yöntemlerin çalışılmasına daha fazla ihtiyaç duyulacaktır. Ekolojik geçitlerin geliştirilmesi, yaban hayatı hareketi ve ekosistem bağlantısı üzerindeki olumsuz etkilerinin azaltılması, hayvan popülasyonlarının kalıcılığı ve temel ekosistem süreçlerinin sürdürülmesi için kritik öneme sahiptir (Beyer ve ark., 2016). Yolların yaban hayatı üzerine etkilerini azaltmak için birçok yöntem bulunmaktadır. Bütün bu yöntemleri olumsuzluğu azaltma etkinliği ile maliyeti ile beraber değerlendirmek gerekmektedir. Ekolojik üst geçitleri veya diğer bu tanıma uygun yaban hayatı geçitleri, ekolojik köprüler, peyzaj köprüleri en maliyetli ama etkinliği yüksek koruma sunan kalıc yöntemlerdir.

Dünya'daki ekolojik köprülerin ilk örneklerine Kuzey Amerika ve Avrupa ülkelerinde rastlanmaktadır. Avrupa'da ilk ekolojik köprü 1950'lerde Fransa'da, en büyüğü 1600 metre uzunluğu ile "Natuurbrug Zanderij Crailoo" Hollanda'da yapılmıştır. Bu ekolojik köprüler geyik, yaban domuzu ve diğer memelilerin yanı sıra nesli tükenmekte olan Avrupa porsuğu için de güvenli bir geçiş sağlamaktadır (Van Wieren ve Worm, 2001). Kanada Alberta'da Central Rocky Dağları'ndaki Banff Milli Parkı'ndan geçen Trans-Kanada Otoyolu üzerinde 24 adet yaban hayatı üst geçidi bulunmaktadır (Tercan, 2017). Türkiye'de ise ilk ekolojik köprü Adana'da Gülek Boğazı'nda yapılmıştır. İstanbul'da Kuzey Anadolu Otoyolu üzerinde farklı konumlarda, Manisa'da İstanbul-i̇zmir Otoyolu ve İzmir'de İzmir-Çeşme Otoyolu üzerinde yeni ekolojik köprüler yapılmıştır. Türkiye'de ilk ekolojik köprüsünün açılmasından bugüne 10 yıl gibi bir süre geçmesine rağmen halen etkinliği hakkında bir bilgi bulunmamaktadır.

Birçok tür için, geçiş bölgeleri ve araç çarpması sonucu ölümler uzaysal olarak kümelenme eğilimindedir, bu da yaban hayvanlarının otoyollardan habitat veya yol özelliklerine bağlı olarak rastgele geçmediğini göstermektedir (Ozcan ve Özkazanç, 2017). Hayvan türleri morfolojik ve davranışsal özellikleri ve habitat tercihlerine bağlı olarak konumsal geçişlerini yapmaktadır (Ramp ve ark., 2006). Bu geçişi etkileyen en önemli etken vejetasyon yapısıdır (Lewis ve ark., 2011). Potansiyel ekolojik köprülerin yer seçimi için kullanılan habitat uygunluk katmanları ve yöntem vejetasyon yapısını desteklemekte ve öncelikli tercih olarak en uygun habitat olan ormanı tercih etmektedir.

Ekolojik köprülerin yer seçiminde yaban hayatı araç çarpışmaları birçok ipucu vermektedir. Özellikle kazaların sıcak noktaları ile peyzaj ve yol özelliklerinin analiz edilmesi veya modellenmesi sadece kazalar hakkında bilgi vermez. Aynı zamanda önlemlerin nasıl alınması gerektiği konusunda da belirleyicidir. İzmir-Çeşme otoyolunda yaban hayatı araç çarpışmalarının nerelerde yoğunlaştığı konusunda veri bulunmamaktadır. Muhtemelen, yapılan ekolojik köprü araçlarla domuzların sıklıkla çatışmaya girdiği noktalar olabilir veya yaralamalı ve ölümlü kazaların olduğu noktalar olabilir. Bu noktalarda gerçekleşen kazaların sebebinin peyzajdan mı kaynaklandığı ya da yol güvenliğinden mi kaynaklandığı konusunda bilimsel bir çalışmanın olmaması yer seçimi noktasında önemli bir eksikliktir. Türkiye'de yaban hayatı araç çarpışmaları üzerine yeterli çalışma bulunmamaktadır. Yapılan araştırmalar ise hangi türlerin kazalara karıştığı üzerinedir (Tok ve ark., 2011; Toyran ve ark., 2018; Bülbül ve ark., 2019; Gözütok ve ark., 2019; Güven, 2019). Köprülerin yer seçiminde kullanılabilecek konumsal ve zamansal bilgi içeren, analiz edilebilir yani sıcak nokta ve model çalışmaları ise (Özcan ve Özkazanç, 2017; 2020; Özcan, 2018) oldukça sınırlıdır. Yaban hayatı araç çarpışmaları konumsal olarak rastgele olup kümelenme eğilimindedir ve en önemlisi de yıllara göre konumsal farklılık göstermektedir (Özcan, 2018). Sadece kaza sıcak noktaları üzerinden hareket etmek yanıltıcı olabilir. Kazaya sebep olan ana faktörün ne olduğunun belirlenmesi basit önlemlerle korumanın yapılabileceğini gösterebilir. 
KGM (2018) hedeflerine göre 2023 yllına kadar mevcut yollara ilave $2370 \mathrm{~km}$ bölünmüş yol ve $1122 \mathrm{~km}$ otoyol yapılması planlanmaktadır. Yol ağının yoğunluğunu düşündüğünüz zaman yaban hayatı araç çarpışma sıcak noktaları, GPS ile yaban hayvanlarının takip edilmesi gibi birçok yöntemin bütün alanlar için yapılmasının mümkün olmadığı açıktır. Elbette bu çalışmalarının modellenmesi birçok avantaj sağlayacaktır. CBS tabanlı bağlantı modelleri bu süreçleri kısaltabildiği gibi daha geniş alanlar içinde kullanılması mümkündür. Uzaktan algılama/CBS/Bağlantı modelleri birlikteliği yaban hayatı gözlemleri ile peyzaj ve yol özelliklerini daha hızlı değerlendirerek azaltma önlemlerinin nerelerde gerekli olduğunu tahmin edebilmektedir. Ekolojik köprülerin nerelerde konumlandırılacağı oldukça önemlidir. Ekolojik geçitler belirli bir alandan geçişi sağlayabilmektedir. Bu yüzden ekolojik köprülerin olumsuz etkileri en aza indirebilmesi için bütün alanı kapsayacak şekilde kompleks olarak konumlandırılması şarttır. Çalışmada sunulan yöntemin en önemli avantajı bütün alandaki uygun geçiş alanlarını vermesidir. İzmir-Çeşme Otoyolu'nun yaklaşık olarak \%8'i potansiyel ekolojik köprü için uygundur. Ama bu dağılımlar belirli alanlarda yoğunlaşmaktadır. Bunun asıl sebebi yolun iki tarafında da orman yapısının hâkimiyetidir.

Son olarak Hepcan ve ark. (2009) İzmir ili, Hepcan ve Özkan (2011) Çeşme Yarımadası, için ekolojik koridorları ve karayolları ile kesiştiği yerleri belirlemiştir. Bu iki çalışma arasında benzerlikler bulunmaktadır. Öncelikli olarak Hepcan (2008) ve Hepcan ve ark. (2009) tarafından İzmir'de yapılan çalışmaları, Türkiye'deki ekolojik koridor planlama çalışmalarının miladı olarak kabul edebiliriz. Kesgin Atak ve Tonyaloğlu (2020) İzmir ilinin genelinde 1990 ile 2018 yılları arasındaki değişimi incelemiş ve kentsel alanların ciddi şekilde artı̆̆ını ortaya çıkarmıştır. Urla Belediyesi (2019) sınırları içerisinde sadece altı yıllık süreçte yaklaşık 7000 konut yapı ruhsatı verilmiştir. Aynı şekilde belirli zaman aralıklarında arazi kullanım değişimlerinin incelenmesi, habitat bağlantılarının nasıl değiştiğini görmek için oldukça önemlidir. Özcan ve Aktaş (2020) Çankırı için zamansal olarak peyzaj koridorlarının yerlerinin değiştiğini belirlemiştir. Sadece koridorların değişmediği aynı zamanda koridorların geçtiği güzergahların da peyzaj dirençlerinin arttığı tespit edilmiştir. Hepcan ve Özkan (2011)'ın çalışması ile bu çalışmanın beraber incelenmesi sadece ekolojik koridorlardaki değişimlerin anlaşılmasını değil aynı zamanda ekolojik köprülerin yer seçimi ile koridorların birlikte planlaması gerektiğini göstermesi açısından oldukça önemlidir. Ekolojik köprülerin yer seçiminde gelecekteki peyzajın nasıl olacağının bilinmesi, köprünün sürekliliğini sağlamak adına önemli bir kriter olacaktır. Özellikle yerleşim ve tarım gelişim bölgelerini göz önünde bulundurulmayan yer seçimleri her zaman risk içerebilmektedir.

\section{ÇIKAR ÇATIŞMASI}

Yazarlar olarak makalenin planlanması, yürütülmesi ve yazılması konusunda herhangi bir çıkar çatışması olmadığını beyan ederiz

\section{YAZAR KATKISI}

Yazarlar olarak makalenin planlanması, yürütülmesi ve yazımı tarafımızca eşit olarak yapılmıştır.

\section{KAYNAKLAR}

Bastille-Rousseau, G., Wall, J., Douglas-Hamilton, I., \& Wittemyer, G. (2018). Optimizing the positioning of wildlife crossing structures using GPS telemetry. Journal of Applied Ecology, 55(4), 2055-2063.

Bekat, L. (1980). Karaburun Akdağ çevresinin flora ve vejetasyonu. Yüksek Lisans Tezi, Ege Üniversitesi, Fen Bilimleri Enstitüsü, İzmir.

Beyer, H. L., Gurarie, E., Börger, L., Panzacchi, M., Basille, M., Herfindal, I., Moorter, B. V., Lele, S. R., \& Matthiopoulos, J. (2016). 'You shall not pass!': quantifying barrier permeability and proximity avoidance by animals. Journal of Animal Ecology, 85(1), 43-53.

Bosch, J., De La Torre, A., Alexandrov, T., Iglesias, I., Miteva, A., \& Muñoz, M. J. (2014). Can habitat suitability predict the presence of wild boar? Suitable land uses vs. georeferenced data in Bulgaria. Journal of Vertebrate Biology, 63(3), 194205.

Bülbül, U, Eroğlu, A, Kutrup, B, Kurnaz, M, Koç, H, \& Odabaş, Y. (2019). Road kills of amphibian and reptile species in Edirne and Kırklareli Provinces of Turkey. Sinop Üniversitesi Fen Bilimleri Dergisi, 4(2), 109-121.

Clevenger, A. P., \& Huijser, M. P. (2011). Wildlife crossing structure handbook: Design and evaluation in North America. (No. FHWA-CFL-TD-11-003). United States. Federal Highway Administration. Central Federal Lands Highway Division. 
COPERNICUS. (2020). CORINE 2000 ve 2018 uydu görüntü veri setleri. https://land.copernicus.eu/pan-european/corine-landcover. Erişim tarihi: 05 Mart 2020.

Cushman, S. A., Lewis, J. S., \& Landguth, E. L. (2013). Evaluating the intersection of a regional wildlife connectivity network with highways. Movement Ecology, 1(1), 12.

Çeşme Kaymakamlığı. (2020). Sosyal durum-eğitim durumu. http://www.cesme.gov.tr/sosyal-durum-egitim-durumu. Erişim tarihi: 15 Aralık 2020.

Dodd, N. L., Gagnon, J. W., Boe, S., \& Schweinsburg, R. E. (2007). Role of fencing in promoting wildlife underpass use and highway permeability. Wildlife and Terrestrial Ecosystems, ICOET 2007 Proceedings, 475-487.

Downs, J. A., \& Horner, M. W. (2012). Enhancing habitat connectivity in fragmented landscapes: Spatial modeling of wildlife crossing structures in transportation networks. Annals of the Association of American Geographers, 102(1), 17-34.

Eigenbrod, F., Hecnar, S. J., \& Fahrig, L. (2009). Quantifying the road-effect zone: threshold effects of a motorway on anuran populations in Ontario, Canada. Ecology and Society, 14(1), 24.

Forman, R. T. (2012). Safe Passages: Highways, Wildlife, and Habitat Connectivity. Island Press.

Forman, R. T., \& Alexander, L. E. (1998). Roads and their major ecological effects. Annual Review of Ecology and Systematics, 29(1), 207-231.

Frank, H. (1969). Shortest paths in probabilistic graphs. Operations Research, 17(4), 583-599.

Glista, D. J., DeVault, T. L., \& DeWoody, J. A. (2009). A review of mitigation measures for reducing wildlife mortality on roadways. Landscape and Urban Planning, 91(1), 1-7.

Gözütok, S., Toyran, K., Yorulmaz, T., 2019. Türkiye'deki memeli hayvanların araç çarpmaları sonucu gördüğü zararlar ve bazı çözüm önerileri. 2nd International Agricultural Congress, Ayaş, Ankara.

Gurrutxaga, M., Lozano, P. J., \& del Barrio, G. (2010). GIS-based approach for incorporating the connectivity of ecological networks into regional planning. Journal for Nature Conservation, 18(4), 318-326.

Günal, N. (1986). Gediz-Büyük Menderes arasındaki sahanın bitki coğrafyası. Doktora Tezi, İstanbul Üniversitesi, Deniz Bilimleri ve Coğrafya Enstitüsü, İstanbul.

Güven, Y. (2019). Çankırı ilinde trafik ve karayollarının memeli hayvanlar üzerine etkisi. Yüksek Lisans Tezi, Çankırı Karatekin Üniversitesi, Fen Bilimleri Enstitüsü, Çankırı.

Helldin, J. O., \& Seiler, A. (2003). Effects of roads on the abundance of birds in Swedish forest and farmland. Wildlife Biology, $6,111-120$.

Hepcan, Ç. C. (2008). Doğa korumada sürdürülebilir bir yaklaşım, ekolojik ağların belirlenmesi ve planlanması: Çeşme-Urla Yarımadası örneği. Doktora Tezi, Ege Üniversitesi, Fen Bilimleri Enstitüsü, İzmir.

Hepcan, Ç. C., \& Özkan, M. B. (2011). Establishing ecological networks for habitat conservation in the case of Çeşme-Urla Peninsula, Turkey. Environmental Monitoring and Assessment, 174(1-4), 157-170.

Hepcan, Ş., Hepcan, Ç. C., Bouwma, I. M., Jongman, R. H., \& Özkan, M. B. (2009). Ecological networks as a new approach for nature conservation in Turkey: a case study of Izmir Province. Landscape and Urban Planning, 90, 143-154.

Hepcan, Ş., Hepcan, Ç. C., Koçman, A., Özkan, M. B., \& Can, Ö. E. (2013). Yaban hayatı koruma bağlamında karakulak (Caracal Caracal) için İzmir ili örneğinde habitat ağları oluşturulması üzerine bir araştırma. Tekirdağ Ziraat Fakültesi Dergisi, 10(1), 29-39.

Horne, J. S., Garton, E. O., Krone, S. M., \& Lewis, J. S. (2007). Analyzing animal movements using Brownian bridges. Ecology, 88(9), 2354-2363.

Huijser, M. P., Kociolek, A. V., McGowen, P. T., Ament, R., Hardy, A., \& Clevenger, A. P. (2007). Wildlife-vehicle collision and crossing mitigation measures: a toolbox for the Montana Department of Transportation (No. FHWA/MT-07-002/811734). Montana. Dept. of Transportation. Research Programs.

Kesgin Atak, B., \& Ersoy Tonyaloğlu, E. (2020). Monitoring the spatiotemporal changes in regional ecosystem health: a case study in Izmir, Turkey. Environmental Monitoring and Assessment, 192, 1-14.

KGM. (2018). Karayolları Genel Müdürlüğü 2019-2023 Stratejik Planı. KGM Strateji Geliştirme Dairesi Başkanlığı, Ankara

KGM. (2020). Devlet Karayolları trafik hacim haritası. https://www.kgm.gov.tr/Sayfalar/KGM/SiteTr/Trafik/TrafikHacimHaritasi. aspx. Erişim tarihi: 12 Mart 2020.

Klein, D. J., \& Randić, M. (1993). Resistance distance. Journal of Mathematical Chemistry, 12(1), 81-95. 
Laurance, W. F., Goosem, M., \& Laurance, S. G. (2009). Impacts of roads and linear clearings on tropical forests. Trends in Ecology \& Evolution, 24(12), 659-669.

Lewis, J. S., Rachlow, J. L., Horne, J. S., Garton, E. O., Wakkinen, W. L., Hayden, J., \& Zager, P. (2011). Identifying habitat characteristics to predict highway crossing areas for black bears within a human-modified landscape. Landscape and Urban Planning, 101(2), 99-107.

McNab, B. K. (1963). Bioenergetics and the determination of home range size. The American Naturalist, 97(894), 133-140.

McRae, B. H., \& Kavanagh, D. M. (2011). Linkage Mapper Connectivity Analysis Software. The Nature Conservancy, Seattle WA.

McRae, B. H., Dickson, B. G., Keitt, T. H., \& Shah, V. B. (2008). Using circuit theory to model connectivity in ecology, evolution, and conservation. Ecology, 89(10), 2712-2724.

McRae, B. H., Hall, S. A., Beier, P., \& Theobald, D. M. (2012). Where to restore ecological connectivity? Detecting barriers and quantifying restoration benefits. PloS one, 7(12), e52604.

Ovaskainen, O. (2013). How to develop the nature conservation strategies for The Netherlands?. De Levende Natuur, 114(2), 59-62.

Özcan, A. U. (2018). Step bölgede mammalia sınıfı yaban hayvanları ile araç çarpışmalarının modellenmesi: Kırıkkale-Çankırı karayolu örneği. Doktora tezi, Bartın Üniversitesi, Fen Bilimleri Enstitüsü, Bartın.

Özcan, A. U., \& Aytaş, İ. (2020) Peyzaj direnç değişimlerinin ekolojik bağlantılar üzerine etkileri: Çankırı örneği. Bartın Orman Fakültesi Dergisi, 22(3), 979-992.

Özcan, A. U., \& Erzin, P. E. (2020). Assessment of GIS-assisted movement patches using LCP for local species: North Central Anatolia Region, Turkey. Cerne, 26(1), 130-139.

Özcan, A. U., \& Özkazanç, N. K. (2017). Identifying the hotspots of wildlife vehicle collision on Çankırı-Kırıkkale Highway during summer. Turkish Journal of Zoology, 41, 722-730.

Özcan, A. U., \& Özkazanç, N. K. (2020) Yaban hayvanı uyarı levhalarının konumlarının değerlendirilmesi Kırıkkale-Çankırı Karayolu Örneği. Bartın Orman Fakültesi Dergisi, 22(1), 208-221.

Panagoda, P. A. B. G., \& Weerasinghe, V. P. A. (2019). A potential habitat corridor for Western Purple-faced Langur between Forest Reserves in Sri Lanka: GIS as a tool in connectivity modelling. Acta Ecologica Sinica, 39(3), 194-201.

Rho, P. (2015). Using habitat suitability model for the wild boar (Sus scrofa Linnaeus) to select wildlife passage sites in extensively disturbed temperate forests. Journal of Ecology and Environment, 38(2), 163-173.

Ruediger, W. (2001). High, wide, and handsome: Designing more effective wildlife and fish crossings for roads and highways. In C. L. Irwin, P. Garrett, \& K. P. McDermott, Proceedings of the 2001 International Conference on Ecology and Transportation, (pp. 509-16). Raleigh: North Carolina State University, Center for Transportation and the Environment.

Rutten, A., Casaer, J., Swinnen, K. R., Herremans, M., \& Leirs, H. (2019). Future distribution of wild boar in a highly anthropogenic landscape: Models combining hunting bag and citizen science data. Ecological Modelling, 411, 108804.

Sáenz-de-Santa-María, A., \& Tellería, J. L. (2015). Wildlife-vehicle collisions in Spain. European Journal of Wildlife Research, 61(3), 399-406.

Scheick, B. K., \& Jones, M. D. (1999). Locating wildlife underpasses prior to expansion of Highway 64 in North Carolina.

Sempéré, A. J., Sokolov, V. E., \& Danilkin, A. A. (1996). Capreolus capreolus. Mammalian Species, 538, 1-9.

Sezer, L. İ., (1993). Karaburun yarımadası fiziki coğrafyası. Doktora Tezi, Ege Üniversitesi, Sosyal Bilimler Enstitüsü, İzmir.

Shae, V. B., \& McRae, B. H. (2008). Circuitscape: a tool for landscape ecology. In G. Varoquaux, T. Vaught, J. Millman (Eds.). Proceedings of the 7th Python in Science Conference (SciPy 2008). California, USA: Pasadena.

Soykan, F., Sezer, L. İ., \& Işık, Ş. (1989). Karaburun Yarımadası'nın doğal özellikleri, tarihsel coğrafyası ve turizm potansiyeli. Ege Üniversitesi Araştırma Fon Saymanlığı, Ege Üniversitesi, İzmir.

Tercan, E. (2017). Karayolu projelerinin hazırlanmasında yaban hayatı geçiş yapılarının değerlendirilmesi. Iğdır Üniversitesi Fen Bilimleri Enstitüsü Dergisi, 7(3), 239-248.

Tok, C. V., Ayaz, D., \& Çiçek, K., (2011). Road mortality of amphibians and reptiles in the Anatolian part of Turkey Turkish Journal of Zoology, 35(6), 851-857.

Toyran, K., Adızel, Ö., \& Azizoğlu, E. (2018). Van Gölü Havzası'ndaki Türkiye memeli türlerinin yol ölümleri. Biyolojik Çeşitlilik ve Koruma, 11(1), 40-44. 
TÜiK. (2020). Türkiye İstatistik Kurumu İzmir nüfus bilgileri. https://biruni.tuik.gov.tr/medas/?kn=95\&locale=tr. Erişim tarihi: 28 Mart 2020.

Urban, D. L., Minor, E. S., Treml, E. A., \& Schick, R. S. (2009). Graph models of habitat mosaics. Ecology Letters, 12(3), $260-273$.

Urla Belediyesi (2019). Urla Belediyesi 2020-2024 Stratejik Plan. Urla Belediyesi, İzmir.

Van Der Ree, R., Smith, D. J., \& Grilo, C. (2015). Handbook of Road Ecology. John Wiley \& Sons.

Van Wieren, S. E., \& Worm, P. B. (2001). The use of a motorway wildlife overpass by large mammals. Netherlands Journal of Zoology, 51(1), 97-105.

Whittington-Jones, B. M., Parker, D. M., Bernard, R. T., \& Davies-Mostert, H. T. (2011). Habitat selection by transient African wild dogs (Lycaon pictus) in northern KwaZulu-Natal, South Africa: implications for range expansion. African Journal of Wildlife Research, 44(2), 135-147.

Wierzchowski, J., Kučas, A., \& Balčiauskas, L. (2019). Application of least-cost movement modeling in planning wildlife mitigation measures along transport corridors: Case study of forests and moose in Lithuania. Forests, $10(10), 831$.

Wilcox, B. A. (1984). Concepts in conservation biology: applications to the management of biological diversity. In J. A. McNeely \& K. R. Miller (Eds.), National Parks, Conservation, and Development: The Role of Protected Areas in Sustaining Society.

Zeller, K. A., McGarigal, K., \& Whiteley, A. R. (2012). Estimating landscape resistance to movement: a review. Landscape Ecology, 27(6), 777-797. 